\title{
EDUCAÇÃO DAS RELAÇÕES ÉTNICO-RACIAIS, EDUCAÇÃO ESCOLAR QUILOMBOLA E EDUCAÇÃO ESCOLAR INDÍGENA NA ESDUCAÇÃO BÁSICA: ESPECIFICIDADES E APROXIMAÇÕES
}

\author{
Education Of Ethnic-Racial Relations, Quilombola School Education and \\ Indigenous School Education in Basic Education: specificities and approaches
}

Educación de Relaciones Étnico-raciales, Educación Escolar de Quilombola y
Educación Escolar Indígena en Educación Básica: especificaciones y enfoques

Candida Soares da Costa*

\section{Resumo}

Nas décadas mais recentes, o Brasil tem avançado no enfrentamento do racismo, a partir do campo educacional, com o estabelecimento de políticas de educação voltadas à Educação das relações étnico-raciais, à educação escolar quilombola e à Educação Escolar Indígena. No entanto, parece haver certo desencontro na efetivação dessas políticas, à medida que são entendidas de modo dissociado uma da outra ou hierárquico entre si. A pesquisa da qual resultou o presente artigo teve por objetivo, tomando por base metodológica a pesquisa de análise documental (LÜDKE, ANDRÉ, 1986) e a análise de conteúdo (BARDIN, 2011), compreender as especificidades e possíveis aproximações ou distanciamentos entre as diretrizes que definem tais políticas. Espera-se que os resultados aqui apresentados possam contribuir ao melhor entendimento das relações existentes entre essas políticas que possa se reverter ao seu fortalecimento, visto que um dos aspectos relevantes da pesquisa é a contribuição ao debate que envolve o tema educação e diferença que problematiza a tomada dos marcadores étnico-raciais como distintivos hierarquizantes na sociedade Brasileira.

Palavras-Chave: Educação das Relações étnico-raciais. Educação Escolar Quilombola. Educação Escolar Indígena.

\begin{abstract}
In the most recent decades, Brazil has advanced in the fight against racism, from the educational field, with the establishment of education policies aimed at Education of ethnic-racial relations, quilombola school education and Indigenous School Education. However, there seems to be a certain mismatch in the effectiveness of these policies, as they are understood in a way that is dissociated from one another or hierarchical among themselves. The research from which the

\footnotetext{
* Doutora em Educação pela Universidade Federal Fluminense. Professora na Universidade Federal de Mato Grosso, onde atua na disciplina Educação das Relações Étnico-Raciais e orienta no Programa de Pós-Graduação em Educação - Mestrado e Doutorado. É líder do Núcleo de Estudos e Pesquisas sobre Relações Raciais e Educação junto ao Diretório dos Grupos de Pesquisa do Brasil-Capes/CNPq. Pesquisadora Associado à Associação Nacional de Pós-Graduação e Pesquisa em Educação (Anped) e à Associação Brasileira de Pesquisadores/as Negros/as (ABPN e integra o projeto de cooperação Procad Amazônia: - UFPA/PPGEDUC-UFMT/PPGE-UFAM/PPGE: Políticas Educacionais, Linguagens e Práticas Culturais na Amazônia.
} 
present article resulted had the objective, taking as a methodological basis the research of documentary analysis (LÜDKE, ANDRÉ, 1986) and content analysis (BARDIN, 2011), to understand the specificities and possible approximations or distances between the guidelines that define such policies. It is hoped that the results presented here may contribute to a better understanding of the relationships between these policies that can be reverted to their strengthening, since one of the relevant aspects of the research is the contribution to the debate that involves the theme of education and difference that questions the issue. taking ethnic-racial markers as hierarchical distinctives in Brazilian society.

KEYWORDS: Education of Ethnic-racial Relations. Quilombola School Education. Indigenous School Education.

\section{Resumen}

En las últimas décadas, Brasil ha avanzado en la lucha contra el racismo, desde el campo educativo, con el establecimiento de políticas educativas dirigidas a la educación de las relaciones étnico-raciales, la educación escolar quilombola y la educación escolar indígena. Sin embargo, parece haber un cierto desajuste en la efectividad de estas políticas, ya que se entienden de una manera disociada entre sí o jerárquica entre sí. La investigación de la que resultó el presente artículo tuvo el objetivo, tomando como base metodológica la investigación del análisis documental (LÜDKE, ANDRÉ, 1986) y el análisis de contenido (BARDIN, 2011), para comprender las especificidades y posibles aproximaciones o distancias entre las pautas. que definen tales políticas. Se espera que los resultados presentados aquí puedan contribuir a una mejor comprensión de las relaciones entre estas políticas que pueden revertirse a su fortalecimiento, ya que uno de los aspectos relevantes de la investigación es la contribución al debate que involucra el tema de la educación y la diferencia que cuestiona el tema. tomando marcadores étnico-raciales como distintivos jerárquicos en la sociedad brasileña.

PALABRAS CLAVE: Educación de las Relaciones Étnico-raciales. Quilombola Educación Escolar. Educación Escolar Indígena.

\section{INTRODUÇÃO}

Diálogo com gestores e operadores de políticas públicas educacionais e de currículo em contextos formativos contínuos, ainda é comum perguntas ou afirmações que demarcam hierarquia, separação ou exclusão entre Educação das relações étnicoraciais, Educação escolar quilombola e Educação escolar indígena como como concorrentes entre si, constituindo-se composições discursivas que, indiscutivelmente, podem resultar no fortalecimento de uma em detrimento de outra ou no enfraquecimento de todas, considerando que vivemos em uma sociedade em que as diferenças decorrentes da diversidade humana ainda se encontra no centro das disputas por reconhecimento e valorização em decorrência do racismo, do etnocentrismo, da colonialidade e de outros processos nos quais se ancoram estruturas voltadas à dominação de diferentes grupos humanos por intermédio da hierarquização das diferenças étnico-raciais. Essas demarcações evidenciam complexidade quanto ao entendimento das políticas educacionais para a valorização e reconhecimento da diversidade humana, visto a persistência da noção biológica de raça como potente marcador social na separação e distinção dos seres humanos. Embora sua vinculação ao 
campo científico se remete ao século XIX, suas consequências ainda se mantêm presentes na atualidade.

A realização da pesquisa se motivou pela necessidade de busca por respostas às seguintes questões: Existem fronteiras demarcadas, separando Educação das relações étnico-raciais, Educação escolar quilombola e Educação escolar indígena? Até que ponto elas se distanciam, se convergem ou se solidarizam? Os discursos que tratam essas políticas de educação e de currículo de forma excludente entre si e que motivaram essas questões, encontram ancoradouro nos documentos orientativos dessas políticas?

Ante essas interrogações, optou-se por realizar uma pesquisa, tendo por objetivo analisar pareceres e resoluções do Conselho Nacional de Educação que constituem as diretrizes que orientam as políticas de atendimento à efetivação de educação das relações étnico-raciais no sistema nacional de ensino, educação escolar quilombola na educação básica e educação escolar indígena. As fontes utilizadas foram: 1- Resolução $\mathrm{CNE} / \mathrm{CP} \mathrm{n}^{\mathrm{o}} 1$, de 17 de junho de 2004 à qual se integra o Parecer CNE/CP no 003 , aprovado em 10 de março de 2004; 2- Resolução CNE/CEB n ${ }^{\circ}$ 8, de 20 de novembro de 2012; 3- Resolução CNE/CEB nº 5, de 22 de junho de 2012 e 4- Parecer CNE/CEB $\mathrm{n}^{\circ} 14 / 2015$, aprovado em 11 de novembro de 2015 .

Pautou-se o processo de geração e de análise de dados, pela orientação metodológica da análise documental, combinada com a Análise de Conteúdo, tomandose por referência Lüdke e André (1986) e Bardin (2011). A pertinência dessa combinação se sustenta na convergência de que, se a análise documental propicia aprofundamento na consistência do documento, a análise de conteúdo possibilita a abertura da mensagem que o documento contém ao entendimento com a densidade propiciada pelos diferentes aspectos de abordagem e de análise às quais o mesmo é submetido. Um dos aspectos relevantes da pesquisa é a contribuição que seus resultados podem disponibilizar ao debate que envolve o tema educação e diferença que problematiza a hierarquização dos marcadores étnico-raciais dos diferentes grupos que constituem o povo brasileiro.

Trata-se de pesquisa realizada no âmbito do projeto "Educação Quilombola: festas, memórias e tradições", tendo por motivação a necessidade de conhecimentos que contribuam à ampliação do entendimento quanto ao objeto e finalidade da Educação das relações étnico-raciais, Educação Escolar quilombola e Educação escolar indígena, evidenciada em debates realizados em contextos formativos com educadores, pesquisadores e operadores de políticas públicas nos quais, muitas vezes, essas políticas aparecem como relacionadas, concorrentes ou prescindíveis entre si em enunciados tais como: "já se trabalhou sobre o negro, agora é sobre os indígenas"; "a 10.639 foi substituída pela 11.645"; ou ainda, "Educação das relações étnico-raciais é uma coisa, Educação escolar quilombola ou Educação escolar indígena é outra".

Diante disso, a pesquisa se fez necessária no sentido de compreender as especificidades e possíveis aproximações ou distanciamentos entre as diretrizes que definem tais políticas. 


\section{Aspectos metodológicos}

Do ponto de vista teórico-metodológico, trata-se de uma pesquisa de abordagem qualitativa, que se utilizou do embasamento teórico da Análise Documental no processo de produção de dados e da Análise de Conteúdo na organização desses dados e na composição das inferências. No que se refere à análise documental, Lüdke e André (1986) consideram que, na pesquisa em educação, todos os materiais escritos podem ser utilizados como fonte.

Estes incluem desde leis e regulamentos, normas, pareceres, cartas, memorandos, diários pessoais, autobiografias, jornais, revistas, discursos, roteiros de programação de rádio e televisão até livros, estatísticas e arquivos escolares (LÜDKE; ANDRÉ, 1986, p. 38).

A opção pela análise documental se deveu ao fato de que as fontes se constituem por documentos que se caracterizam pela durabilidade enquanto orientativos das políticas às quais se referem, podendo, desse modo, "[...] ser consultados várias vezes e inclusive servir de base a diferentes estudos [...]" (LÜDKE; ANDRÉ, 1986, p. 38). Em relação à análise de conteúdo, a escolha se ancorou no entendimento quanto a sua relevância enquanto suporte teórico-metodológico à construção das inferências sobre os conteúdos simbólicos, contidos nos documentos analisados.

Bardin considera que, em análise de conteúdo, as coisas não estão prontas. $\mathrm{O}$ que existe, segundo ela, são "algumas regras de base, por vezes dificilmente transponíveis". (BARDIN, 2011, p. 36). Observa-se de relevante importância a afirmação dessa autora no que se refere à adequação da técnica da análise de conteúdo às necessidades e objetivos da pesquisa.

A técnica de análise de conteúdo adequada ao domínio e ao objetivo pretendidos tem de ser reinventada a cada momento, exceto para usos simples e generalizados, como é o caso do escrutínio próximo da decodificação e de respostas a perguntas abertas de questionários cujo conteúdo é avaliado rapidamente por temas (BARDIN, 2011, p. 36).

Nesse sentido, ela atribui a seguinte definição à análise de conteúdo:

Um conjunto de técnicas de análise das comunicações visando obter por procedimentos sistemáticos e objetivos de descrição do conteúdo das mensagens, indicadores quantitativos ou não que permitam a inferência de conhecimentos relativos às condições de produção/recepção (variáveis inferidas) dessas mensagens (BARDIN. 2011, p. 48).

Sob essa perspectiva, considera-se pertinente a opção pela análise de conteúdo como orientação metodológica à elaboração das inferências consonantes aos objetivos e problematizações que a investigação procurou corresponder.

Quatro documentos foram escolhidos para composição do corpus da pesquisa: 1- Resolução CNE/CP $\mathrm{n}^{\circ} 1$, de 17 de junho de 2004, que definem as Diretrizes Curriculares Nacionais para a Educação das Relações Étnico-Raciais e para o Ensino de História e Cultura Afro-Brasileira e Africana, ao qual se integra o Parecer CNE/CP ${ }^{\circ}$ 003, aprovado em 10 de março de 2004; 2- Resolução CNE/CEB no 8, de 20 de novembro de 2012, que definem Diretrizes Curriculares Nacionais para a Educação 
Escolar Quilombola na Educação Básica; 3- Resolução CNE/CEB no 5, de 22 de junho de 2012, que define Diretrizes Curriculares Nacionais para a Educação Escolar Indígena na Educação Básica e 4- Parecer CNE/CEB no 14/2015, aprovado em 11 de novembro de 2015, que estabelece Diretrizes Operacionais para a Implementação da História e das Culturas dos Povos Indígenas na Educação Básica, em decorrência da Lei $\mathrm{n}^{\mathbf{o}}$ $11.645 / 2008$.

Tratam-se de documentos oficiais, que, em termos de suas finalidades, pressupõem-se durabilidade e confiabilidade à possibilidade diversa de inferências acerca dos conteúdos de suas mensagens, posto que se constituem principais documentos orientativos quanto às especificidades de educação e de currículo às quais se vinculam o objeto da pesquisa.

Feita a definição da abordagem metodológica, fez-se a escolha dos procedimentos de geração e análise de dados. Assim, fez-se necessário o procedimento de leitura dinâmica de cada documento, o que possibilitou primeiro contato com os conteúdos textuais com finalidade investigativa, bem como a observância da pertinência dos mesmos à constituição do corpus de documentos selecionados para análise. Em seguida, passou-se à leitura de imersão, através da qual se buscou maior precisão no entendimento de cada texto no sentido de fazer emergir os elementos de análise necessários ao procedimento das inferências, sem perder de vista os três polos cronológicos em torno dos quais, segundo Bardin (2011), se organizam as fases de análise de conteúdo: 1) a pré-análise, isto é, a definição do corpus, que é "[...] o conjunto dos documentos tidos em conta para serem submetidos aos procedimentos analíticos." (BARDIN, 2011, p. 126), a reformulação dos objetivos e das problematizações e a organização e constituição de processo de condução dos trabalhos, visando, ao curso da pesquisa, ouvir o que dizem os documentos, proceder análise e inferências devidamente fundamentadas, considerando as interfaces que tais documentos estabelecem entre si; 2) a exploração do material, que "[...] consiste essencialmente em operações de codificação, decomposição ou enumeração, em função de regas previamente formuladas" (BARDIN, 2011, p. 131); e 3) o tratamento dos resultados, a inferência e a interpretação, que diz respeito a tornar significativos e válidos os dados brutos, colocando em evidência as informações obtidas por intermédio da análise.

Ao todo, foram definidas as seguintes unidades temáticas: características dos documentos; Destinação/abrangência; Objetivo/Foco; Proposições centrais dos documentos; Especificidades de cada documento e suas relações ente si. A composição e operacionalização das unidades temáticas foram feitas mediante composição descritivas dos documentos conforme modelo expresso no quadro 1.

Quadro 1: Modelo organizativo de registro temático sobre os conteúdos textuais

\begin{tabular}{|c|c|c|c|c|}
\hline \multirow{2}{*}{ Unidades temáticas } & \multicolumn{4}{|c|}{ Documentos analisados } \\
\cline { 2 - 5 } & 1 & 2 & 3 & 4 \\
\cline { 2 - 5 } & Resolução & Resolução & Resolução & Parecer \\
& CNE/CP n $^{\circ}$ & CNE/CEB n & CNE/CEB n & CNE/CEB n \\
& $1 / 2004$ & $8 / 2012$ & $5 / 2012$ & $14 / 2015$ \\
\hline Características dos documentos & & & & \\
\hline Destinação/abrangência & & & & \\
\hline
\end{tabular}




\begin{tabular}{|c|l|l|l|l|}
\hline Objetivo/Foco & & & & \\
\hline $\begin{array}{c}\text { Proposições centrais dos } \\
\text { documentos }\end{array}$ & & & & \\
\hline Especificidades dos documentos & & & & \\
\hline
\end{tabular}

Fonte: Arquivo pessoal da pesquisadora.

A elaboração do quadro se fez sob intenção de dupla finalidade: a classificação dos dados e análise das mensagens que os dados possibilitam identificar. A partir dos registros obtidos nesse quadro, foi possível estabelecer comparações e elaborar as inferências. Bardin (2011) considera que embora haja semelhança de procedimentos utilizados na análise documental e na análise de conteúdo, há de se observar diferenças essenciais, dentre as quais a de que "A análise documental faz-se principalmente, por classificação-indexação; a análise de categoria temática é, entre outras, uma das técnicas da análise de conteúdo.”. (BARDIN, 2011, p. 52). Se por um lado, a análise documental possibilitou a passagem de uma documentação primária, composta pelos pareceres e resoluções, para um documento secundário, elaborado como representação de conteúdo dessa documentação; a análise de conteúdo, permitiu melhor entendimento por meio da análise das mensagens observadas.

Cumprida a intenção de disponibilizar os principais aspectos sobre o percurso percorrido no processo de desenvolvimento da pesquisa, passa-se, na sequência, a um breve entendimento sobre os marcos do debate e, na sequência, o resultado da análise dos dados produzidos.

\section{Os marcos do debate}

Como ponto de partida para situar melhor o contexto de produção da pesquisa, fez-se pertinente relembrar alguns marcos do debate, dos quais, aparentemente, se originaram os entendimentos expressos nos discursos instigadores da pesquisa. Observa-se que, em consequência de demandas da sociedade brasileira, especialmente do movimento social negro, no ano de 2003, por intermédio da Lei $\mathrm{n}^{\circ} 10.639 / 2003$, foi decretada pelo Congresso Nacional e sancionada pelo presidente da República, a alteração da Lei de Diretrizes e Bases da Educação Nacional (LDB n ${ }^{\circ}$ 9394/1996), tornando obrigatório o ensino sobre História e Cultura Afro-Brasileira nos estabelecimentos de ensino fundamental e médio, oficiais e particulares no território brasileiro. Em decorrência disso, o Ministério da Educação, por intermédio do Conselho Nacional de Educação, emitiu o Parecer CNE/CP nº 003/2004, considerando pertinência da matéria e recomendando a instituição de Diretrizes Curriculares Nacionais para a Educação das Relações Étnico-Raciais e para o Ensino de História e Cultura AfroBrasileira e Africana. Esse Parecer, foi foi aprovado por unanimidade pelo Conselho Pleno do Conselho Nacional de Educação no dia 10 de março de 2004 e homologado pelo Ministro da Educação em 19 de maio de 2004. Diante disso, O Conselho Nacional de Educação/Conselho Pleno/DF, instituiu as Diretrizes Curriculares Nacionais para a Educação das Relações Étnico-Raciais e para o Ensino de História e Cultura AfroBrasileira e Africana por intermédio da Resolução $\mathrm{n}^{\mathbf{0}}$ 1, de 17 de junho 2004, incorporando à resolução, o Parecer CNE/CP nº 003/2004. 
Cinco anos depois, a LDB/96 foi novamente alterada, desta vez pela Lei $\mathrm{n}^{\circ}$ 11.645/2008, que incidiu-se sobre o artigo 26A, trazido pela Lei $\mathrm{n}^{\mathrm{o}} 10.639 / 03$, tornando obrigatória a inclusão no currículo oficial da rede de ensino a temática "História e Cultura Afro-Brasileira e Indígena". Embora a Lei n ${ }^{\circ} 11.645 / 08$ não tenha efeito de revogação da Lei ${ }^{\circ} 10.639 / 03$, muitos comentários equivocados começaram a circular, cujos efeitos se repercutem ainda na atualidade. Semelhante ocorrência também se observa em relação ao advento da Resolução $\mathrm{MEC/CNE/CP}$ n $^{\circ}$ 8, de 20 de novembro de 2020, que estabelece Diretrizes Curriculares Nacionais para a Educação Escolar Quilombola na Educação Básica, haja vista a presença de discursos que opõem ou relativizam a importância da Educação das Relações Étnico-Raciais em contextos e territórios quilombolas, visto que passam a ter diretrizes de educação específicas.

Vale destacar que a luta da população negra, incluindo a quilombola, assim como a dos indígenas, por reconhecimento enquanto agentes históricos, atravessa toda a história brasileira, impactando, no século XX, a Constituição Federal de 1988, que trouxe avanços importantes para todos esses grupos no que se refere à garantia de direitos. No que se refere ao campo da educação, obteve-se, especificamente, no que diz respeito à educação escolar indígena no âmbito de seus territórios, a garantia de escolarização "[...] em suas línguas maternas e processos próprios de aprendizagem" (Art. 210) e, em termos de abrangência geral, a garantia do direito da consideração pela educação escolar das "[...] contribuições das diferentes culturas e etnias para a formação do povo brasileiro" (Art. 242). Como desdobramento desse artigo, a LDB n. 9394/96 definiu no Art. 26, $\S 4^{\circ}$, que o ensino da História do Brasil “[...] levará em conta as contribuições das diferentes culturas e etnias para a formação do povo brasileiro, especialmente das matrizes indígena, africana e europeia".

No que se refere às contribuições indígenas, a LDB estabeleceu orientações no sentido de efetivação do preceito constitucional de garantia do direito de que a educação escolar passasse a lhe ser ofertada em "línguas maternas e processos de aprendizagem próprios", fortalecida por meio do desenvolvimento "de programas integrados de ensino e pesquisa, para oferta de educação escolar bilíngüe e intercultural com os seguintes objetivos: I - proporcionar aos índios, suas comunidades e povos, a recuperação de suas memórias históricas; a reafirmação de suas identidades étnicas, a valorização de suas línguas e ciências; II - garantir aos índios, suas comunidades e povos, o acesso às informações, conhecimentos técnicos e científicos da sociedade nacional e demais sociedades indígenas e não-índias" (Art. 78); apoio técnico e financeiro dos "[...] sistemas de ensino no provimento da educação intercultural à comunidades indígenas, desenvolvendo programas integrados de ensino e pesquisa", com objetivos de: I - fortalecer as práticas sócio-culturais e a língua materna de cada comunidade indígena; II - manter programas de formação de pessoal especializado, destinado à educação escolar nas comunidades indígenas; III - desenvolver currículos e programas específicos, neles incluindo os conteúdos culturais correspondentes às respectivas comunidades; IV - elaborar e publicar sistematicamente material didático específico e diferenciado.”. (Art. 79).

Curioso é que, a mesma LDB $n^{\circ}$ 9394/96, não apresentou quaisquer desdobramentos orientativo em relação ao tratamento das matrizes africanas e afrobrasileiras na educação escolar. Segundo Costa (2013), em decorrência disso e, 
consequente mobilização do movimento negro brasileiro, em 1998 o então Deputado Federal Paulo Paim:

[...] buscou institucionalizar mecanismos que garantissem possibilidades efetivas de inclusão no currículo escolar brasileiro conhecimentos sobre África e, consequentemente, sobre os africanos na diáspora e seus descendentes. Visava abrir caminhos para que estudantes pudessem acessar conhecimentos ainda não contemplados no processo educativo, tendo em vista a relevância africana na constituição da nação brasileira. Protocolou, junto ao Conselho Nacional de Educação, o Processo No. 23001.000003/9815, propondo "a inclusão da disciplina "História da África" nos currículos mínimos obrigatórios da educação básica e dos cursos de graduação das áreas de Humanidades e Ciências Sociais". (COSTA, 2013, p. 95).

A proposta foi submetida à relatoria, que resultou no Parecer $\mathrm{N}^{\circ}$. 88/98, contrário à aprovação da proposta. Esse parecer obteve aprovação do Conselho Pleno do Conselho Nacional de Educação em 14 de outubro de 1998. Ainda segundo Costa (2013), a rejeição propiciou, novas articulações do movimento negro e de intelectuais.

[...] comprometidos com a luta contra o racismo na sociedade brasileira, propiciaram à deputada Esther Grossi, em coautoria com o deputado Ben-Hur Ferreira, propor à Mesa Diretora da Câmara dos Deputados, em 11 de março de 1999, o Projeto de Lei 259/1999, que dispunha sobre a obrigatoriedade da inclusão, no currículo da Rede de Ensino, da temática "História e Cultura Afro-Brasileira". (COSTA, 2013, p. 96).

Decorrente desse tenso processo de busca pelo cumprimento do dispositivo constitucional de 1988, em 9 de janeiro de 2003, após ter sido decretada pelo Congresso Nacional, a Lei $\mathrm{n}^{\mathbf{0}} 10.639$ foi sancionada com vetos pelo Presidente da República, imprimindo alteração na Lei no 9.394, de 20 de dezembro de 1996, para tornar obrigatória a inclusão da temática "História e Cultura Afro-Brasileira" no currículo oficial dos estabelecimentos de ensino fundamental e médio, oficiais e particulares brasileiros. Seus desdobramentos normativos assentados no princípio de que o racismo se constitui entrave à própria consolidação da democracia brasileira, propõe uma educação das Relações Étnico-Raciais e, embora com foco na população negra, reconhece os indígenas como igualmente necessários de reconhecimento na sociedade brasileira em relação a outros grupos, que gozam do privilégio do reconhecimento, propiciado pelo processo de racialização e hierarquização dos seres humanos.

Sobre a abrangência dessa Lei, tendo por foco a inclusão de História e Cultura Afro-Brasileira no currículo escolar, novas tensões entraram em pauta: no dia 19 de março de 2003, a então deputada federal Mariângela Duarte apresentou no plenário um projeto de lei, propondo alteração na LDB $n^{\circ}$ 9394/96, especificamente sobre o artigo 26 A, inserido pela Lei $\mathrm{n}^{\circ} 10.639 / 2003$, "para incluir, no currículo oficial da Rede de Ensino, a obrigatoriedade da temática "História e Cultura Afro-Brasileira e Indígena". A propositora alegava que a Lei $n^{\circ} 10.639 / 2003$ cuja sanção presidencial havia sido saudada pela sociedade, era objeto de crítica pela comunidade indígena, que não se considerava "[...] contemplada com a previsão de disciplinas para os alunos conhecerem a realidade indígena do País". Esse projeto passou a tramitar, pela identificação Projeto de Lei, PL 433/2003, transformada na Lei Ordinária 11645, de 10 de março de 2008. 
Após tramitação, o PL 433/2003 foi transformado na Lei Ordinária 11.645/2008, de 10 de março de 2008, tendo por finalidade alterar a modificação efetuada pela Lei $\mathrm{n}^{\circ}$ 10.639/2003 para inserir também a obrigatoriedade de inserção da temática indígena no currículo oficial da rede de ensino conforme aponta Costa (2013). Embora a Lei $n^{\circ}$ 11.6456/08 se constitua uma Norma de Natureza Geral, igualmente à Lei $n^{\circ} 10.639 / 03$, não teve a função de revogar os efeitos desta, posto que seu efeito incidiu apenas sobre a redação do artigo 26A. Entender esses aspectos é de fundamental importância no que diz respeito tanto à formulação quanto à operação de políticas curriculares voltadas à toda população brasileira, no que tange ao reconhecimento e valorização dos diferentes segmentos da população.

Em decorrência da Lei no 11.645/2008, o conselho Nacional de Educação voltou a atuar sobre a pauta educação das relações étnico-raciais, tendo por pauta central o reconhecimento e valorização dos indígenas enquanto agentes na história brasileira. Estabelece-se, assim, em 2015, as Diretrizes Operacionais para a Implementação da História e das Culturas dos Povos Indígenas na Educação Básica, em Decorrência da Lei ${ }^{\circ} 11.645 / 2008$.

Em relação aos avanços constitucionais, dois outros desdobramentos podem ser observados no campo educacional: 1- a definição das Diretrizes Curriculares Nacionais para a Educação Escolar Quilombola na Educação Básica; 2- a definição das Diretrizes Curriculares Nacionais para a Educação Escolar Indígena na Educação Básica. Entretanto, discursos apreendidos no cotidiano evidenciam a existência de certo distanciamento entre os documentos de formulação das políticas e as práticas tangentes à concomitante efetivação dessas políticas.

\section{Os documentos e suas relações ente si}

Conforme já anunciado na abordagem metodológica deste artigo, as análises aqui apresentadas se pautam em dados obtidos a partir das seguintes fontes documentais: 1- Diretrizes Curriculares Nacionais para a Educação das Relações Étnico-Raciais e para o Ensino de História e Cultura Afro-Brasileira e Africana foi instituída pela Resolução CNE/CP $\mathrm{n}^{\mathrm{o}}$ 1, de 17 de junho de 2004; 2- a Resolução CNE/CEB $n^{\circ}$ 8, de 20 de novembro de 2012, que definem Diretrizes Curriculares Nacionais para a Educação Escolar Quilombola na Educação Básica; 3- a Resolução CNE/CEB $n^{\circ} 5$, de 22 de junho de 2012, que define Diretrizes Curriculares Nacionais para a Educação Escolar Indígena na Educação Básica e 4- o Parecer CNE/CEB no 14/2015, aprovado em 11 de novembro de 2015, que estabelece Diretrizes Operacionais para a Implementação da História e das Culturas dos Povos Indígenas na Educação Básica, em decorrência da Lei nº 11.645/2008.

São documentos que se caracterizam como orientativos, que estabelecem diretrizes à formulação e execução de políticas educacionais e curriculares que tenham como princípio o reconhecimento e a valorização das diferenças étnico-raciais, em oposição às bases racistas, colonialistas e etnocêntricas vigentes no imaginário e nas práticas sociais e, consequentemente, na educação escolar brasileira. Podem ser organizados em dois grupos: os de abrangência geral e os de abrangência específica. 
Os documentos de abrangência geral constituem as diretrizes curriculares nacionais de educação das relações étnico-raciais e compõem-se pelos seguintes documentos: 1) a Resolução CNE/CP n ${ }^{\circ} 1$, de 17 de junho de 2004, que estabelece as Diretrizes Curriculares Nacionais para a Educação das Relações Étnico-Raciais e para o Ensino de História e Cultura Afro-Brasileira e Africana, à qual se integra o Parecer CNE/CP 3/2004; e 2) o Parecer CNE/CEB no 14/2015, que define as Diretrizes Operacionais para a Implementação da História e das Culturas dos Povos Indígenas na Educação Básica, em decorrência da Lei nº 11.645/2008.

São orientações com efeitos sobre os níveis municipais, estaduais e federal, devendo ser levadas em conta no âmbito das políticas públicas de educação e de currículo referentes a todos os níveis e às modalidades de ensino no âmbito dos sistemas de ensino público e privado. Não têm como foco a educação escolar de negros ou de índios, mas a reeducação de toda a sociedade brasileira, compreendendo a:

[...] divulgação e produção de conhecimentos, a formação de atitudes, posturas e valores que eduquem cidadãos orgulhosos de seu pertencimento étnico-racial - descendentes de africanos, povos indígenas, descendentes de europeus, de asiáticos - para interagirem na construção de uma nação democrática, em que todos, igualmente, tenham seus direitos garantidos e sua identidade valorizada (BRASIL, 2004).

Nessa mesma direção, entende-se que o ensino de conteúdos referentes à história e cultura afro-brasileira e dos povos indígenas brasileiros no âmbito de todo o currículo escolar propicia:

[...] a compreensão da dinâmica sociocultural da sociedade brasileira visa à construção de representações sociais positivas que valorizem as diferentes origens culturais da população brasileira como um valor e, ao mesmo tempo, crie um ambiente escolar que permita a manifestação da diversidade de forma criativa e transformadora na superação de preconceitos e discriminações étnico-raciais (BRASIL, 2015).

Observa-se como um dos princípios sobre o qual se assenta esse conjunto de documentos normativos, que fundamentam e orientam a educação das relações étnicoraciais, é o da incompatibilidade do racismo e do etnocentrismo com a consolidação do Estado Democrático de Direito, definidos pela Constituição Federal de 1988. Entendese com isso que, mesmo negro e indígenas tendo suas especificidades, são ambos dois segmentos da população brasileira sobre os quais impactam, historicamente, o peso produzido pelo processo de racialização da humanidade em que ambos foram situados nas escalas mais inferiores da hierarquização dos seres humanos, produzida pelo cientificismo do século XIX e pelo constructo de uma nação republicana brasileira que, embora se beneficie das produções culturais desses dois segmentos constitutivos do povo brasileiro, primou por mecanismos voltados à eliminação material e simbólica de ambos. O não reconhecimento do racismo como fator operativo e determinante sobre as condições de produção de vida de brancos negros e indígenas, que resulta em vantagens para a população branca em detrimento dos negros e indígenas se constitui uma forma de enfraquecimento das forças que, aliançadas por meio de negociação e defesa de objetivos comuns, podem impactar positivamente a favor de ambos na luta por direitos e contra as desigualdades no acesso e exercício desses direitos. 
São considerados documentos de abrangência específica: 1) a Resolução CNE/CEB $\mathrm{n}^{\circ}$ 8, de 20 de novembro de 2012, que definem Diretrizes Curriculares Nacionais para a Educação Escolar Quilombola na Educação Básica; e 2) a Resolução CNE/CEB n ${ }^{\circ}$ 5, de 22 de junho de 2012, que define Diretrizes Curriculares Nacionais para a Educação Escolar Indígena na Educação Básica. Essa caracterização corresponde ao fato de que orientam formulação e execução de políticas educacionais e curriculares que visem ao atendimento dos povos indígenas e quilombolas, considerando suas respectivas especificidades. Tratam-se, portanto, de fundamentos e orientação à formulação e execução de políticas de reparação e de afirmação de direitos no campo educacional ante os danos historicamente causados a essas populações, especialmente no que se refere à preservação identitárias e culturais.

\begin{abstract}
Políticas de reparações e de reconhecimento formarão programas de ações afirmativas, isto é, conjuntos de ações políticas dirigidas à correção de desigualdades raciais e sociais, orientadas para oferta de tratamento diferenciado com vistas a corrigir desvantagens e marginalização criadas e mantidas por estrutura social excludente e discriminatória. Ações afirmativas atendem ao determinado pelo Programa Nacional de Direitos Humanos, (2) bem como a compromissos internacionais assumidos pelo Brasil, com o objetivo de combate ao racismo e a discriminações, tais como: a Convenção da UNESCO de 1960, direcionada ao combate ao racismo em todas as formas de ensino, bem como a Conferência Mundial de Combate ao Racismo, Discriminação Racial, Xenofobia e Discriminações Correlatas de 2001 (BRASIL, 2004, p. 12).
\end{abstract}

Entende-se que tais documentos constituem-se aportes de fundamental importância ao alcance de objetivos de políticas curriculares e educacionais que que tenham como foco o reconhecimento e valorização das diferenças étnico-raciais como valor social, não se conflitando entre si nem em relação aos seus destinatários, nem em relação aos seus objetivos e finalidades. A Educação das Relações Étnico-Raciais tem como finalidade a educação das relações sociais como um todo, a partir do ensino de conteúdo de história e cultura afro-brasileiras e indígenas em todos os níveis da educação, abarcando todos os sistemas de ensino, tanto público quanto particular, o que significa que deve abranger também as escolas onde se desenvolve educação escolar quilombola, assim como aquelas que se destinam à educação escolar indígenas. Igualmente, a Educação Escolar Quilombola, por si mesma, não se contrasta, nem se opõem, à Educação Escolar Indígena ou vice-versa, sob nenhum aspecto. Portanto, o tratamento equitativo dessas orientações na formulação e execução das políticas públicas são fundamentalmente necessárias, à medida que estão voltadas à superação de processos de desumanização e de produção de desigualdades sociais que geram prejuízos a toda a sociedade.

\title{
Considerações finais
}

Ao deter-se na busca de entendimento desse arcabouço legal, compreende-se que as afirmações que motivaram a pesquisa da qual resultam o presente artigo demonstram total falta de amplitude na compreensão a respeito das finalidades dessas diretrizes, posto que estas não comportam orientações que se imponham ou se oponham umas às outras, nem que se excluem entre si, posto que suas especificidades não constituem fronteiras de impedimento de convergência de esforços que coadunem na coexistência 
de fortalecimento de uma e de outra. O que significa que, discursos que estabelecem oposição entre Educação da Relações Étnico-Raciais, Educação Escolar Quilombolas e Educação Escolar Indígenas cumprem apenas a função colonialista de dificultar possibilidade de estabelecimento de alianças dos grupos tratados como minoritários, em prol do fortalecimento da luta pelos seus direitos, à medida que contribuem ao aumento de dificuldades para que tais grupos percebam as diferentes dimensões que propiciam suas aproximações em prol de negociações de objetivos comuns.

Discursos que tratam de forma excludentes entre si Educação da Relações Étnico-Raciais, Educação Escolar Quilombolas e a Educação Escolar Indígenas, a exemplo dos que impulsionaram as questões motivadoras da pesquisa que se finaliza com este artigo não encontram ancoradouro nos documentos orientativos. Demonstram por parte dos agentes discursivos, no mínimo, ausência de adequado conhecimento dos conteúdos das concepções das diretrizes que as orientam, requerendo, por parte de formuladores, gestores das políticas educacionais em geral, o necessário estabelecimento de ações voltadas à contínua formação, dos agentes executores dessas políticas.

\section{REFERÊNCIAS}

BARDIN, Laurence. Análise de conteúdo. São Paulo: Edições 70, 2011.

BRASIL. Ministério da Educação. Secretaria Especial de Políticas de Promoção da Igualdade Racial. Diretrizes Curriculares Nacionais para a Educação das Relações Étnico-Raciais e para o Ensino de História e Cultura Afro-Brasileira e Africana. Brasília, DF, 2004. 35 p. Disponível em: <http://portal.inep.gov.br/informacao-dapublicacao/-/asset_publisher/6JYIsGMAMkW1/document/id/488171>. Acesso em 15/01/2019.

BRASIL. Ministério da Educação. Conselho Nacional de Educação. Parecer CNE/CEB no 8/2012, aprovado em 20 de novembro de 2012. Disponível em:

$<$ http://portal.mec.gov.br/escola-de-gestores-da-educacao-basica/323-secretarias112877938/orgaos-vinculados-82187207/12988->. Acesso em 11/12/2020.

BRASIL. Ministério da Educação. Resolução CNE/CP nº 5, de 22 de junho de 2012. Define Diretrizes Curriculares Nacionais para a Educação Escolar Indígena na Educação Básica.. Disponível em: <http://portal.mec.gov.br/pec-g/323-secretarias112877938/orgaos-vinculados-82187207/18692-educacao-indigena>. Acesso em 02/01/2019.

BRASIL. Ministério da Educação. Parecer CNE/CEB nº 14/2015, aprovado em 11 de novembro de 2015 - Diretrizes Operacionais para a implementação da história e das culturas dos povos indígena na Educação Básica, em decorrência da Lei no 11.645/2008. Disponível em: <http://portal.mec.gov.br/pec-g/323-secretarias-112877938/orgaosvinculados-82187207/18692-educacao-indigena>. Acesso em 02/01/2019. 
BRASIL. Presidência da República. Casa Civil. Lei n ${ }^{\circ}$ 9.394, de 20 de dezembro de 1996. Estabelece as diretrizes e bases da educação nacional. Disponível em <http://www.planalto.gov.br/ccivil_03/leis/19394.htm>. Acesso em 10/01/2019.

BRASIL. Câmara Federal. Projeto de Lei - PL 259/1999. Disponível <https://www.camara.leg.br/proposicoesWeb/fichadetramitacao?idProposicao=15223>. Acesso em 25/01/2020.

BRASIL. Senado Federal. Projeto de Lei - PL 433/2003. Disponível em $<$ https://www25.senado.leg.br/web/atividade/materias/-/materia/75737>. Acesso em 25/01/2020.

BRASIL. Presidência da República. Casa Civil. Lei $n^{\circ}$ 10.639, de 9 de janeiro de 2003. Altera a Lei no 9.394, de 20 de dezembro de 1996, que estabelece as diretrizes e bases da educação nacional, para incluir no currículo oficial da Rede de Ensino a obrigatoriedade da temática "História e Cultura Afro-Brasileira", e dá outras providências. Disponível em <http://www.planalto.gov.br/ccivil_03/leis/2003/110.639.htm>. Acesso em 10/01/2019.

BRASIL. Presidência da República. Casa Civil. Lei no 11.645, de 10 março de 2008. Altera a Lei no 9.394, de 20 de dezembro de 1996, modificada pela Lei no 10.639, de 9 de janeiro de 2003, que estabelece as diretrizes e bases da educação nacional, para incluir no currículo oficial da rede de ensino a obrigatoriedade da temática "História e Cultura Afro-Brasileira e Indígena". Disponível em <http://www.planalto.gov.br/ccivil_03/_Ato2007-2010/2008/Lei/L11645.htm>. Acesso em 10/01/2019.

BRASIL. Ministério da Educação. Conselho Nacional de Educação. Parecer CNE/CEB $n^{o}$ 2/2007, aprovado em 31 de janeiro de 2007. Disponível em $<$ http://portal.mec.gov.br/escola-de-gestores-da-educacao-basica/323-secretarias112877938/orgaos-vinculados-82187207/12988->. Acesso em 11/01/2019.

COSTA, Candida Soares da. Educação para as relações étnico-raciais: planejamento escolar e literatura no Ensino Médio. Cuiabá: EdUFMT, 2013.

COSTA, Candida Soares da. Lei n ${ }^{\circ}$ 10.639/2003: dez anos de implementação do currículo de educação das relações étnico-raciais. Momento - Diálogos em Educação, v. 22: Educação, ensino e diversidade etnicorracional: leis, normas e práticas educativas os 10 anos da lei 10.639/03, n. 1, p. 17-34, jan./jun. 2013. Disponível em <https://periodicos.furg.br/momento/issue/archive>. Acesso em 24/01/2019.

LÜDKE, Menga; ANDRÉ, Marli E. D. A. Pesquisa em educação: abordagens qualitativas. São Paulo: EPU, 1986. (Temas básicos de educação e ensino).

Recebido em: 21/02/2019

Aprovado em: 26/04/2019 